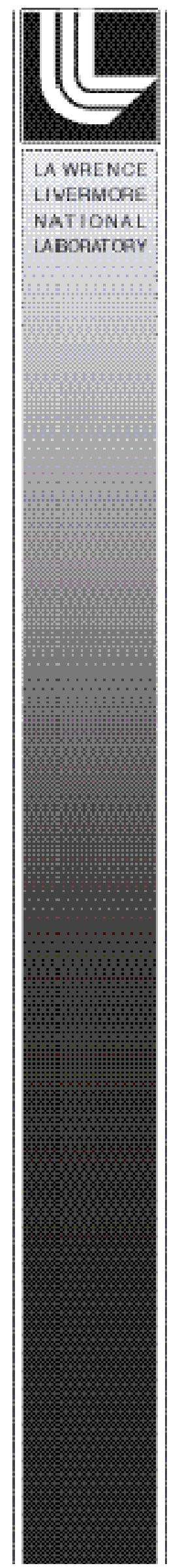

\title{
Effects of titanium additions to austenitic ternary alloys on microstructural evolution and void swelling
}

\author{
T. Okita and W. G. Wolfer \\ Lawrence Livermore National Laboratory \\ F. A. Garner \\ Pacific Northwest National Laboratory \\ N. Sekimura \\ University of Tokyo
}

2003.12

Philosophical Magazine A 


\section{Disclaimer}

This document was prepared as an account of work sponsored by an agency of the United States Government. Neither the United States Government nor the University of California nor any of their employees, makes any warranty, express or implied, or assumes any legal liability or responsibility for the accuracy, completeness, or usefulness of any information, apparatus, product, or process disclosed, or represents that its use would not infringe privately owned rights. Reference herein to any specific commercial product, process, or service by trade name, trademark, manufacturer, or otherwise, does not necessarily constitute or imply its endorsement, recommendation, or favoring by the United States Government or the University of California. The views and opinions of authors expressed herein do not necessarily state or reflect those of the United States Government or the University of California, and shall not be used for advertising or product endorsement purposes. 


\title{
Effects of titanium additions to austenitic ternary alloys on microstructural evolution and void swelling
}

\author{
T. Okita ${ }^{1}$ and W. G. Wolfer \\ Lawrence Livermore National Laboratory, Livermore, CA, 94550,USA \\ F. A. Garner \\ Pacific Northwest National Laboratory, Richland, WA, 99352,USA \\ and N. Sekimura \\ University of Tokyo, Tokyo, Japan
}

\begin{abstract}
Ternary austenitic model alloys were modified with 0.25 wt. \% titanium and irradiated in FFTF reactor at dose rates ranging over more than two orders in magnitude. While lowering of dose rate strongly increases swelling by shortening the incubation dose, the steady state swelling rate is not affected by dose rate. Although titanium addition strongly alters the void microstructure, swelling at $\sim 420^{\circ} \mathrm{C}$ does not change with titanium additions, but the sensitivity to dose rate is preserved.
\end{abstract}

\footnotetext{
${ }^{1}$ Corresponding Author;

(TEL) +1-925-422-5909, (FAX)+925-423-0785

(E-mail) okita1@1lnl.gov
} 


\section{INTRODUCTION}

Since Johnston and his co-workers [1976] found significant differences in void swelling between model austenitic alloys and commercial alloys by using ion-irradiation, considerable efforts have been devoted to clarify the effect of minor elements on swelling in austenitic alloys [Bates and Johnston 1977, Gessel and Rowcliff 1977, Garner and Brager 1988, Garner 1994, Herschbach et al. 1993]. Systematic experiments show that some minor elements such as titanium [Kawanishi and Ishino 1988, 1991, Muroga et al. 1988, 1994, Sekimura and Ishino 1991, 1994, Watanabe et al. 1994, 1996], phosphorus [Watanabe et al. 1993, 1994, 1995, 1996, Muroga et al. 1994] and silicon [Sekimura et al. 1992, Watanabe et al. 1995] can drastically decrease swelling, but the level of suppression is strongly dependent on both solute concentration and especially irradiation temperature [Garner and Kumar 1987, Muroga et al. 1989, Garner et al. 1993]. In this study, we will evaluate the effect of titanium additions on microstructural evolution and on swelling. Titanium is an oversized atom in austenitic alloys compared to the major elements $(\mathrm{Fe}, \mathrm{Cr}$ and $\mathrm{Ni})$ and therefore is expected to mainly interact with vacancies [Watanabe et al. 1988]. This is believed to suppress void nucleation, especially at higher irradiation temperatures.

Recently, Okita et al. reported on irradiation results for pure ternary austenitic alloys which showed a significant enhancement of void nucleation and 
swelling at low dose rates when irradiated at $\sim 420^{\circ} \mathrm{C}$ [Okita et al. 2001, 2002, 2003a]. In this study, we present similar results on titanium-modified ternary alloy irradiated side by side in FFTF/MOTA with the pure ternary alloys over the same wide range of dose rates and for irradiation temperatures of $387-444^{\circ} \mathrm{C}$. The aim of these experiments was to elucidate the role of titanium on void swelling and to reveal possible synergy of titanium additions with the dose rate influence on microstructural evolution.

\section{EXPERIMENTS}

The detailed experimental procedures are presented elsewhere [Okita et al. 2002, 2003]. Therefore, in this paper, they are only briefly reviewed.

$\mathrm{Fe}-15 \mathrm{Cr}-16 \mathrm{Ni}$ and $\mathrm{Fe}-15 \mathrm{Cr}-16 \mathrm{Ni}-0.25 \mathrm{Ti}$ (wt.\%) were made from the high purity elements of $\mathrm{Fe}, \mathrm{Cr}, \mathrm{Ni}$ and $\mathrm{Ti}$ by arc-melting. No precipitates were observed by TEM in the pre-irradiated samples.

The specimens were irradiated with fast neutrons in the FFTF reactor over a wide range of dose rates which varied from $8.9 \times 10^{-9} \mathrm{dpa} / \mathrm{sec}$ to $1.7 \times 10^{-6}$ $\mathrm{dpa} / \mathrm{sec}$. The cumulative doses ranged from $0.23 \mathrm{dpa}$ to $67.8 \mathrm{dpa}$, depending on the difference in dose rate and irradiation time. The irradiation temperatures were between 387 to $444{ }^{\circ} \mathrm{C}$ and nearly independent of dose rate. The detailed irradiation conditions are summarized in Table 1.

[Insert Table 1 about here] 
After irradiation, immersion density measurements were carried out to estimate the swelling, followed by TEM observation with 200kV electron beam energy.

\section{RESULTS}

Figure 1 shows the swelling in the $\mathrm{Fe}-15 \mathrm{Cr}-16 \mathrm{Ni}-0.25 \mathrm{Ti}$ alloys at seven different dose rates and as a function of cumulative dose. Lower dose rates are seen to produce more swelling by shortening the incubation dose for the onset of steady-state swelling in the titanium-modified alloy, while the steady state swelling rate of $1 \% / \mathrm{dpa}$ persists independent of dose rate [Garner 1994]. Figure 2 expands the scale of the cumulative dose to better visualize the data for low dose rates. Again, a steady state swelling of $\sim 1 \% / \mathrm{dpa}$ can be discern for doses less than $1 \mathrm{dpa}$. The incubation dose for the onset of steady state swelling therefore varies from $<1.0$ to $\sim 60.0 \mathrm{dpa}$ as the dose rate rises over more than two orders of magnitude.

\section{[Insert Figure 1 about here]}

\section{[Insert Figure 2 about here]}

Figure 3 shows the dose dependence of the void microstructure in Fe$15 \mathrm{Cr}-16 \mathrm{Ni}-0.25 \mathrm{Ti}$. Note that only three different dose rates are shown for reasons of clarity, corresponding to the lowest, the medium, and the highest dose rate. Voids can be observed even in the specimen irradiated to only $0.23 \mathrm{dpa}$ at the lowest dose rate. These small voids appear to be distributed homogeneously in 
the matrix and to nucleate without precipitates attached to them. Void sizes significantly increase with dose at each dose rate, but the void density does not significantly increase. Figure 4 shows the void density and average diameter as a function of the cumulative dose. Compared at a fixed dose rate, void densities modestly increase with increasing dose, while on the other hand, void sizes rise very rapidly. Note, however, that at the highest dose rate, the average void diameter appears to decline somewhat with dose. This is not the result of shrinking voids, but caused by further nucleation of small voids during the second cycle.

[Insert Figure 3 about here]

[Insert Figure 4 about here]

At all dose rates tested, it can clearly be observed in Figure 5 that titanium additions strongly suppress the void nucleation, but they compensate this with an increase in void size. So in spite of its strong influence on void microstructure, the effect of dose rate on swelling is not altered by titanium but remains remarkably similar to that of the base ternary alloy, as shown in Figure 6.

[Insert Figure 5 about here]

[Insert Figure 6 about here]

More importantly, when the incubation dose is defined as the intercept dose when extrapolating swelling to $0 \%$ with a $1 \% / \mathrm{dpa}$ swelling rate, then Figure 7 reveals the same linear dependence of the incubation dose on dose rate for 
both alloys. This means that the irradiation time required to reach the steady state swelling is nearly independent of dose rate, and the steady state swelling starts at about $2.4 \times 10^{7} \mathrm{sec}$ for ternary alloy and at $1.7 \times 10^{7} \mathrm{sec}$ for titaniummodified alloys for each and every irradiation condition in this experiment, as shown in Figure 8.

[Insert Figure 7 about here] [Insert Figure 8 about here]

Figure 9 shows a typical dislocation microstructure in the titaniummodified alloy. Both faulted loops, perfect loops and network dislocations are observed after the first cycle of irradiation, and with increasing dose, some faulted loops grow very large and unfault, and become part of the dislocation network.

\section{[Insert Figure 9 about here]}

Figure 10 shows the total dislocation density in the titanium-modified alloys for a wide range of dose rates as a function of cumulative dose. Lower dose rates are seen to enhance dislocation evolution. This is mainly caused by the growth of dislocation loops which strongly depends on dose rate [Watanabe et al. 1988, Kiritani 1989, Muroga et al. 1990]. Figure 11 shows the dislocation density divided into loop and network dislocation line lengths up to $30 \mathrm{dpa}$. The loop line length decreases with increasing doses at every dose rate tested, because as dislocation loops grow large enough they unfault and form network 
dislocations. Therefore, the network dislocation density increases with dose, and the rate of increase is higher at lower dose rate.

\section{[Insert Figure 10 about here]}

[Insert Figure 11 about here]

We observe significant differences in loop evolution by titanium additions as shown in Figure 12. Even at a very low dose for lower dose rates, loops grow much faster compared to the base ternary alloys, and this results in earlier unfaulting. Therefore, at every dose rate tested, loop densities decrease with dose in titanium-modified alloys, and the rate of decrease is higher at lower dose rate.

The total dislocation density, on the contrary, is not strongly affected by titanium addition as shown in Figure 13.

[Insert Figure 12 about here] [Insert Figure 13 about here]

\section{DISCUSSIONS}

Previous studies compared the temperature dependence of the void density and average void diameter for the titanium-modified alloy with those for the pure ternary alloys at $43.8 \mathrm{dpa}$ and for $1.7 \times 10^{-6} \mathrm{dpa} / \mathrm{sec}$, as is shown in Figure 14 [Sekimura and Ishino 1991, 1994]. Titanium addition lowers the void density relative to the pure ternary, but it increases the void diameter monotonically throughout the temperature range covered in that study. It appears 
as if titanium additions increase the effective irradiation temperature by $\sim 50^{\circ} \mathrm{C}$, as void densities and void diameters for titanium-modified alloys irradiated at $427^{\circ} \mathrm{C}$ nearly match those of the pure ternary if irradiated at $\sim 480^{\circ} \mathrm{C}$.

\section{[Insert Figure 14 about here]}

Titanium is an oversized atom among the major elements in austenitic alloys, and is expected to diffuse via vacancy migration, thereby being subject to the inverse Kirkendall effect. Titanium is also known to be a fast diffusing species, diffusing faster in Giron by a factor of 7.6 times or more than Fe [Oikawa 1982]. Therefore, the effective diffusion coefficient for vacancy migration will be elevated by titanium additions.

Accounting for the interaction between titanium and vacancies, the effective diffusion coefficient of vacancies is given by [Garner and Wolfer 1981] $D_{V}^{e f f}=\left(D_{v}+K C_{S} D_{S}\right) /\left(1+K C_{S}\right)$

where $D_{v}$ is the diffusion coefficient for migration of a free vacancy, and $D_{s}$ is the diffusion coefficient for a solute-vacancy pair migration. We write $D_{s}=n D_{v}$, where $n$ is an enhancement factor for titanium self-diffusion in [-iron. $C_{s}$ is the solute concentration, and $K=12 \cdot \exp \left(E_{b} / k T\right)$ is the mass action constant for the solute-vacancy dissociation in an FCC lattice, and $E_{b}$ is the solute-vacancy binding energy. The ratio of $D_{v}^{\text {eff }}$ to $D_{v}$, $\square$ can therefore be written as $\square=\frac{D_{v}^{e \text { eff }}}{D_{v}}=\frac{1+n \cdot K \cdot C_{S}}{1+K \cdot C_{S}}$ 
In this study, $C_{s}$ is $\sim 0.0031$. We now ask what irradiation temperature higher than $420{ }^{\circ} \mathrm{C}$ would produce in the pure ternary alloy an equivalent void microstructure as is observed in the titanium-modified alloy also irradiated at 420 ${ }^{\circ} \mathrm{C}$. This effective irradiation temperature is then defined by $\frac{1}{T_{\text {eff }}}=\frac{1}{T} \square \frac{k}{E_{v}{ }^{m}} \log (\square$

When we insert the vacancy migration energy and binding energy, $E_{v}{ }^{m}$ and $E_{b}$ as $1.2 \mathrm{eV}$ and $0.3 \mathrm{eV}$ respectively, which is the acceptable range [Dimitrov et al. 1982, Kuramoto et al. 1986, Watanabe et al.1988, Okita and Wolfer 2003b], $n$ is estimated to be about 20 . This value is almost three times higher than previously measured value of 7.6 at temperature of $1300 \mathrm{~K}$ and above. Titanium enhances vacancy migration more at lower temperature than at higher temperature.

Since the effect of titanium addition on void swelling is equivalent to an increase in the effective irradiation temperature, it does not change the dose rate effect on swelling. It is worthwhile to emphasize again that lowering of dose rate proportionally decrease the incubation dose, and that once the incubation is complete, the steady state swelling rate of $1 \% / \mathrm{dpa}$ is constant throughout the dose rate range of $10^{-6}$ to $10^{-8} \mathrm{dpa} / \mathrm{sec}$. 
Figure 15 shows the temperature dependence of the swelling for the identical ternary alloy and titanium-modified alloy at $43.8 \mathrm{dpa}$ with $1.7 \times 10^{-6}$ dpa/sec, namely the highest dose rate [Sekimura and Ishino 1991, 1994]. This includes the $420^{\circ} \mathrm{C}$ irradiation data reported in this paper. Note that the peak swelling temperature for the ternary alloy is $\sim 520^{\circ} \mathrm{C}$. Below this temperature, swelling drops with temperature. Therefore, it is natural that an increase in effective irradiation temperature by titanium addition results in an increase in swelling, as shown in Figure 16, and in Table 2 for previous studies. Considering all studies, however, it is seen that the effect of titanium addition on swelling at $420^{\circ} \mathrm{C}$ is relatively small compared to that at $520^{\circ} \mathrm{C}$ and $600^{\circ} \mathrm{C}$. At higher temperature, strong suppression of swelling by titanium has been observed in previous fast breeder reactor studies [Garner 1994].

\section{[Insert Figure 15 about here]}

[Insert Figure 16 about here]

\section{[Insert Table 2 about here]}

It is interesting that, at the highest dose rate, further void nucleation did occur during the second cycle of irradiation, although plenty of voids had formed during the first cycle of irradiation and had grown to large sizes, as large as $100 \mathrm{~nm}$. Both small and large voids co-exist, and this indicates that the void nucleation and growth proceed simultaneously. These two evolutionary stages of void swelling cannot be separated as originally envisioned in the classical rate theories. 
Faulted dislocation loops as shown in Figure 9 are surprisingly large in the titanium-modified alloys, in fact as large as $180 \mathrm{~nm}$ in diameter. One would expect that there is a critical size for the faulted loops to convert to perfect loops, as determined by the stacking fault energy (SFE) [Saada 1963]. According to dislocation theory, this critical loop radius $r$ can be used to estimate the SFE as [Hull and Bacon 1984]

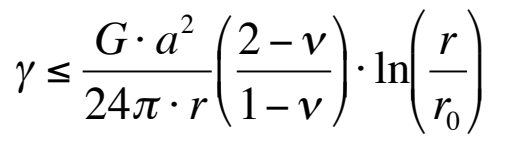

The materials parameters in this relationship are defined in Table 3 together with appropriate values. For the largest loops observed in this experiment, $r \sim 90 \mathrm{~nm}$, and using it in the equation above, a stacking fault energy for this alloy is calculated to be less than $6 \mathrm{~mJ} / \mathrm{m}^{2}$. This value is extremely small and much lower than measured values for austenitic steel which are in the range of $25-40 \mathrm{~mJ} / \mathrm{m}^{2}$ [Gallagher 1970, Reiley 1981, Garner 1994]. This discrepancy is too large and it suggests to us that these very large faulted loops observed in this experiment are metastable, that the unfaulting process can not be thermally activated, and that it requires high internal stresses to overcome the shear transformation barrier from faulted to perfect loop [Kubota et al. 2003].

[Insert Table 3 about here] 


\section{SUMMARY}

$\mathrm{Fe}-15 \mathrm{Cr}-16 \mathrm{Ni}-0.25 \mathrm{Ti}$ alloys were irradiated in FFTF over a wide range of dose rates and at $387-444{ }^{\circ} \mathrm{C}$ for either one of two irradiation cycles. The microstructure generated by the irradiation are evaluated and compared with earlier results reported for alloys without titanium additions but exposed to identical irradiations. As noted in the earlier results, lower dose rates again enhanced void swelling by shortening the incubation dose. However, once the steady state swelling rate of $1 \% / \mathrm{dpa}$ is reached, dose rate dependence disappears. The incubation dose for the onset of steady state swelling is again found to change linearly with dose rate. These trends are the same as for the ternary alloy irradiated side by side with the titanium-modified alloys. Titanium addition strongly lowers void nucleation over a wide range of dose rates. However, it compensates this by enhancing void growth. Titanium atoms are estimated to diffuse 20 times or more faster than Fe atoms, and the binding energy between vacancies and titanium atoms is $0.3 \mathrm{eV}$ or higher. Although there are clear differences in microstructure with titanium addition, Titaniium does not affect macroscopic swelling behavior at $\sim 420{ }^{\circ} \mathrm{C}$ over a wide range of dose rates. 


\section{ACKNOWLEDGEMENTS}

This work was supported by Monbusho, the Japanese Ministry of Education, Science and Culture under the FFTF-MOTA collaboration and the JUPITER program (Japan-USA Program for Irradiation Testing for Fusion Research), by the US Department of Energy, Office of Fusion Energy under Contract DE-AC06-76RLO 1830 with Pacific Northwest National Laboratory, and by a NERI grant with the Lawrence Livermore National Laboratory under contract No W-7405-ENG-48 with the DOE. Additional financial support for T. Okita was provided by Nuclear Fuel Industries Ltd. The authors are pleased to acknowledge the contributions of PNNL employees Ruby Ermi and Elaine Dieffenbacher for specimen retrieval and preparation.

\section{REFERENCES}

Bates, J. F., and Johnston, W. G., 1977, Radiation Effects in Breeder Reactor Structural Materials, 625.

Dimitrov, O., and Dimitrov, C., 1982, J. nucl. Mater., 105, 39.

Gallagher, P. C. J., 1970, Met. Trans., 1, 2429. 
Garner, F. A., and Wolfer, W. G., 1981, J. nucl. Mater., 102, 143.

Garner, F. A., and Kumar, A. S., 1987, Effects of Radiation on Materials, ASTM STP 955, 289.

Garner, F. A., and Brager, H. R., 1988, J. nucl. Mater., 155-157, 833.

Garner, F. A., Miyahara, K., Newkirk, J. W., and Kinoshita, C., 1993, J. nucl. Mater., 199, 132.

Garner, F. A., 1994, Irradiation Performance of Cladding and Structural Steels in Liquid Metal Reactors, Vol 10A, edit by R. W. Cahn, P. Hassen and E. J. Kramer, VCH Publisher, Weinheim, Chapter 6, Material Science and Technology, pp. 419.

Gessel, G. R., and Rowcliff, A. F., 1977, Radiation Effects in Breeder Reactor Structural Materials, 431.

Herschbach, K., Schneider, W., and Ehrlich, K., 1993, J. nucl. Mater., 203, 233.

Hull, D., and Bacon, D. J., 1984, Introduction to dislocations, third edition, Chapter 5, pp.106, Pergamon Publisher 
Johnston, W. G., Lauritzen, T., Rosolowski, J. H., and Turkalo, A. M., 1976, Radiation Damage in Metals. ASM.

Kawanishi, H., and Ishino, S., 1988, J. nucl. Mater., 155-157, 806.

Kawanishi, H., and Ishino, S., 1991, J. nucl. Mater., 179-181, 534.

Kiritani, M., 1989, J. nucl. Mater., 169, 89.

Kubota, A., Okita, T., Caturla, M. J., and Wolfer, W. G., 2003, in preparation.

Kuramoto, E., Tsukada, N., Aono, Y., Takenaka, M., Takano, Y., Yoshida, H., and Shiraishi, K., 1986, J. nucl. Mater., 141-143, 647.

Muroga, T., Araki, K., Miyamoto, Y., and Yoshida, N., 1988, J. nucl. Mater., 155$157,1118$.

Muroga, T., Garner, F. A., and McCarthy, J. M., 1989, J. nucl. Mater., 168, 109.

Muroga, T., Watanabe, H., and Yoshida, N., 1990, J. nucl. Mater., 174, 282. 
Muroga, T., Watanabe, H., and Yoshida, N., 1994, J. nucl. Mater., 212-215, 482.

Oikawa, H., 1982, Technology Reports, Tohoku University, 47. No. 2, 215.

Okita, T., Sekimura, N., Garner, F. A., Greenwood, L. R., Wolfer, W. G., and Isobe, Y., 2001, Proceedings of the $10^{\text {th }}$ International Symposium on Environmental Degradation of Materials in Nuclear Power Systems, on CD with no pages

Okita, T., Sato, T., Sekimura, N., Garner, F. A., and Greenwood, L. R., 2002, J. nucl. Mater., 307-311, 322.

Okita, T., Wolfer, W. G., Garner, F. A., and Sekimura, N., 2003a, submitted to Philo. Mag.

Okita, T., and Wolfer, W. G., 2003b, submitted to J. nucl. Mater.,

Reiley, T. C., 1981, Scripta Metallurgica vol. 15, 313.

Saada, G. V., 1963, Proceedings of the International Conference on Crystal Lattice Defects, Conference Journal of the Physical Society of Japan. Vol. 18, Supplement III, 41. 
Sekimura, N., and Ishino, S., 1991, J. nucl. Mater., 179-181, 542.

Sekimura, N., Garner, F. A., and Newkirk, J. W., 1992, J. nucl. Mater., 191-194, 1244.

Sekimura, N., and Ishino, S., 1994, Effects of Radiation on Materials, ASTM STP 1175, 992.

Watanabe, H., Aoki, A., Murakami, H., Muroga, T., and Yoshida, N., 1988, J. nucl. Mater., 155-157, 815.

Watanabe, H., Muroga, T., and Yoshida, N., 1993, Mater. Trans, JIM, vol. 34, No.11, 1012.

Watanabe, H., Muroga, T., and Yoshida, N., 1994, J. nucl. Mater., 212-215, 503.

Watanabe, H., Garner, F. A., Muroga, T., and Yoshida, N., 1995, J. nucl. Mater., 225, 76.

Watanabe, H., Muroga, T., and Yoshida, N., 1996, J. nucl. Mater., 228, 261. 


\section{Figure Captions}

Figure 1

Swelling in Fe-15Cr-16Ni-0.25Ti irradiated in FFTF/MOTA at $\sim 420^{\circ} \mathrm{C}$ for a wide range of dose rates as a function of cumulative dose. Dose rates in MOTA$2 \mathrm{~A}$ are indicated. Each swelling data comes from either density measurement (above $10 \%$ swelling) or TEM observation (below $10 \%$ swelling).

Figure 2

Swelling in Fe-15Cr-16Ni-0.25Ti irradiated in FFTF/ MOTA at $\sim 420^{\circ} \mathrm{C}$ with the cumulative dose up to $10 \mathrm{dpa}$. Dose rates in MOTA-2A are indicated. At the lower dose rates, the steady state swelling starts from the very low cumulative dose.

Figure 3

Dose dependence of void microstructure in Fe-15Cr-16Ni-0.25Ti irradiated in FFTF/MOTA at three different dose rates.

The lowest dose rates are $8.9 \times 10^{-9} \mathrm{dpa} / \mathrm{sec}$ at $436^{\circ} \mathrm{C}$ in MOTA-2A and $2.2 \times 10^{-8}$ dpa/sec at $444{ }^{\circ} \mathrm{C}$ in MOTA-2B.

The medium dose rates are $3.1 \times 10^{-7} \mathrm{dpa} / \mathrm{sec}$ at $411^{\circ} \mathrm{C}$ in MOTA-2A and $3.0 \mathrm{x}$ $10^{-7} \mathrm{dpa} / \mathrm{sec}$ at $410^{\circ} \mathrm{C}$ in MOTA-2B. 
The highest dose rates are $1.7 \times 10^{-6} \mathrm{dpa} / \mathrm{sec}$ at $427^{\circ} \mathrm{C}$ in MOTA-2A and $1.4 \times 10$ ${ }^{-6} \mathrm{dpa} / \mathrm{sec}$ at $408^{\circ} \mathrm{C}$ in MOTA-2B.

Note that the irradiation history for the medium dose rates are slightly different between MOTA-2A and MOTA-2A \& 2B irradiations.

Figure 4

(a) Void density, and (b) average void diameter for a wide range of dose rates as a function of cumulative dose in $\mathrm{Fe}-15 \mathrm{Cr}-16 \mathrm{Ni}-0.25 \mathrm{Ti}$ irradiated in FFTF/MOTA at $\sim 420^{\circ} \mathrm{C}$. Dose rates in MOTA-2A are indicated.

Figure 5

Comparison of void microstructure between Fe-15Cr-16Ni and Fe-15Cr$16 \mathrm{Ni}-0.25 \mathrm{Ti}$.

(a) $8.9 \times 10^{-9} \mathrm{dpa} / \mathrm{sec}$ at $436^{\circ} \mathrm{C}$ in MOTA-2A and $2.2 \times 10^{-8} \mathrm{dpa} / \mathrm{sec}$ at $444^{\circ} \mathrm{C}$ in MOTA-2B.

(b) $1.7 \times 10^{-6} \mathrm{dpa} / \mathrm{sec}$ at $427^{\circ} \mathrm{C}$ in MOTA-2A and $1.4 \times 10^{-6} \mathrm{dpa} / \mathrm{sec}$ at $408^{\circ} \mathrm{C}$ in MOTA-2B.

Figure 6 
Comparison of swelling between $\mathrm{Fe}-15 \mathrm{Cr}-16 \mathrm{Ni}$ and $\mathrm{Fe}-15 \mathrm{Cr}-16 \mathrm{Ni}-0.25 \mathrm{Ti}$ irradiated side by side in FFTF/MOTA at $\sim 420^{\circ} \mathrm{C}$ for a wide range of dose rates. Dose rates in MOTA-2A are indicated.

Figure 7

Dose rate dependence of the incubation dose for the onset of steady state swelling. Note that an average dose rate for MOTA-2A and $2 \mathrm{~B}$ is chosen. The incubation doses are proportional to dose rate for both alloys irradiated in FFTF/MOTA at $\sim 420^{\circ} \mathrm{C}$.

Figure 8

Irradiation time required to reach the steady state swelling for $\mathrm{Fe}-15 \mathrm{Cr}-16 \mathrm{Ni}$ and $\mathrm{Fe}-15 \mathrm{Cr}-16 \mathrm{Ni}-0.25 \mathrm{Ti}$. Note that the time is almost independent of dose rate, demonstrating that the steady state swelling starts at a certain time.

Figure 9

Typical dislocation microstructure observed in Fe-15Cr-16Ni-0.25Ti irradiated in FFTF/MOTA at 436 and $444^{\circ} \mathrm{C}$. The faulted loops, perfect loops and the network dislocations are observed. Note that the diameters of the faulted loops are as large as $\sim 180 \mathrm{~nm}$. 
Figure 10

Total dislocation density in Fe-15Cr-16Ni-0.25Ti irradiated in FFTF/MOTA at $\sim 420^{\circ} \mathrm{C}$ as a function of cumulative dose. Dose rates in MOTA-2A are indicated.

Figure 11

Loop line length and network dislocation density in Fe-15Cr-16Ni-0.25Ti irradiated in FFTF/MOTA at $\sim 420^{\circ} \mathrm{C}$ for a wide range of dose rates as a function of cumulative dose. Dose rates in MOTA-2A are indicated. Note that the loop line length decreases with increasing dose, whereas the network dislocation density increases with dose. And the rate of the increase in network dislocation density is higher at lower dose rates.

Figure 12

Effects of titanium addition on dislocation morphologies. Dose rates in MOTA-2A are indicated.

(a) loop density, and (b) average loop diameter

Figure 13

Comparison of total dislocation density between $\mathrm{Fe}-15 \mathrm{Cr}-16 \mathrm{Ni}$ and $\mathrm{Fe}-$ $15 \mathrm{Cr}-16 \mathrm{Ni}-0.25 \mathrm{Ti}$ irradiated in FFTF/MOTA at $\sim 420^{\circ} \mathrm{C}$ for a wide range of dose 
rates as a function of cumulative dose. Titanium addition does not strongly affect the total dislocation density.

Figure 14

Temperature dependence of void microstructure for Fe-15Cr-16Ni and Fe15Cr-16Ni-0.25Ti irradiated in FFTF/MOTA at $\sim 43.8 \mathrm{dpa}$ with $1.7 \times 10^{-6} \mathrm{dpa} / \mathrm{sec}$.

(a) Void density, and (b) average void diameter.

Titanium addition decreases the void density, however increases their size.

Figure 15

Temperature dependence of swelling for Fe-15Cr-16Ni and Fe-15Cr-16Ni0.25Ti irradiated in FFTF/MOTA at $\sim 43.8 \mathrm{dpa}$ with $1.7 \times 10^{-6} \mathrm{dpa} / \mathrm{sec}$. At $\sim 420^{\circ} \mathrm{C}$, titanium addition does not suppress swelling, however somehow increases swelling. Increasing the irradiation temperature monotonically decreases the swelling in the titanium-modified alloy.

Figure 16

Comparison of swelling between $\mathrm{Fe}-15 \mathrm{Cr}-16 \mathrm{Ni}$ and $\mathrm{Fe}-15 \mathrm{Cr}-16 \mathrm{Ni}-0.25 \mathrm{Ti}$ irradiated in FFTF/MOTA at $\sim 420^{\circ} \mathrm{C}$ for a wide range of dose rate. Dose rates in MOTA-2A are indicated. 
(a) Lower doses and lower dose rates, (b) Higher doses and higher dose rates.

At $\sim 420^{\circ} \mathrm{C}$, titanium addition often increases the swelling, especially at lower dose rates. 


\section{Table captions}

\section{Table 1}

Irradiation conditions in this experiment

\section{Table 2}

Previous neutron irradiation studies addressing the effect of titanium addition to pure ternaries on swelling at $\sim 400^{\circ} \mathrm{C}$

\section{Table 3}

Typical values for the calculation of the stacking fault energy 


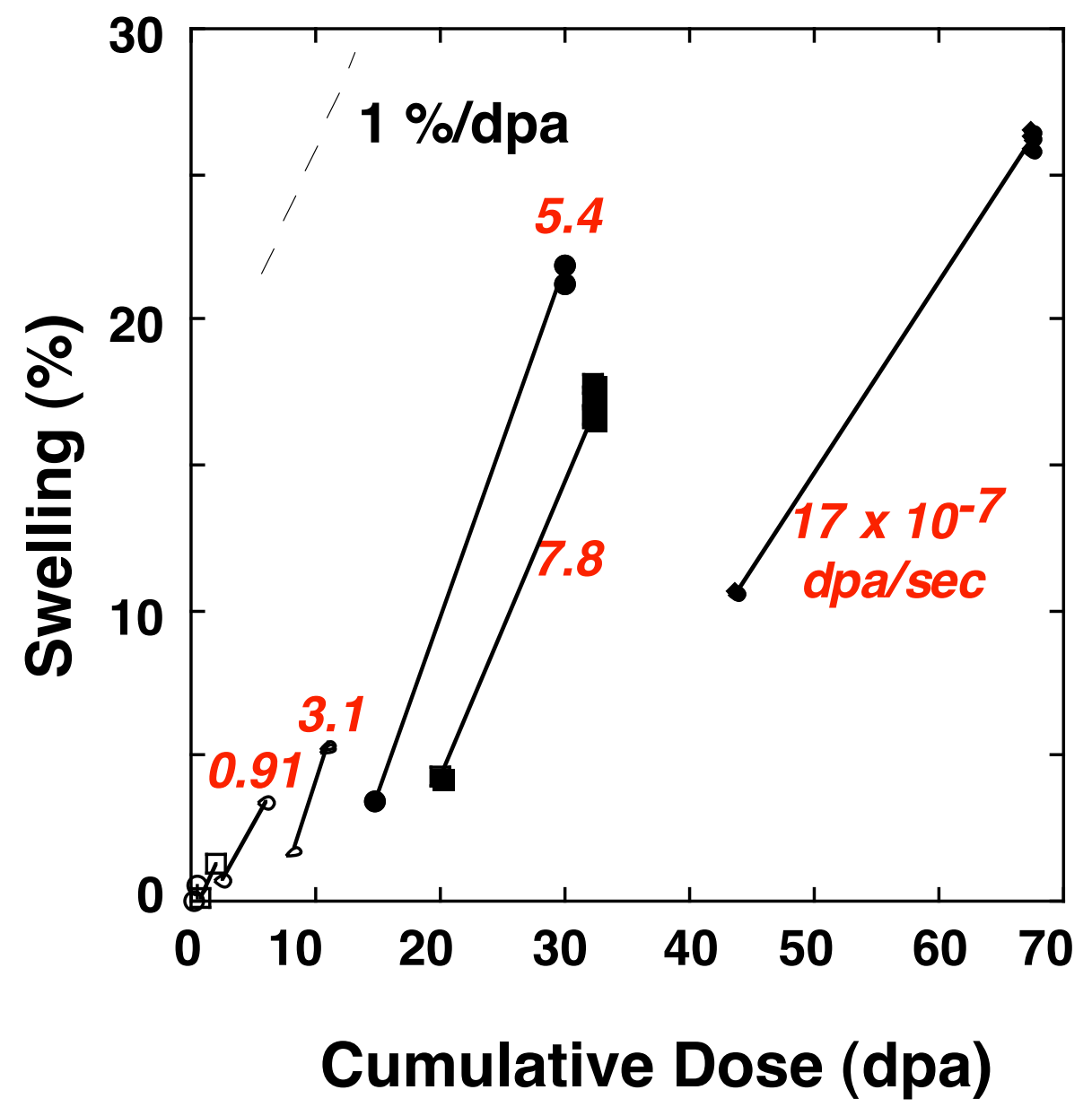




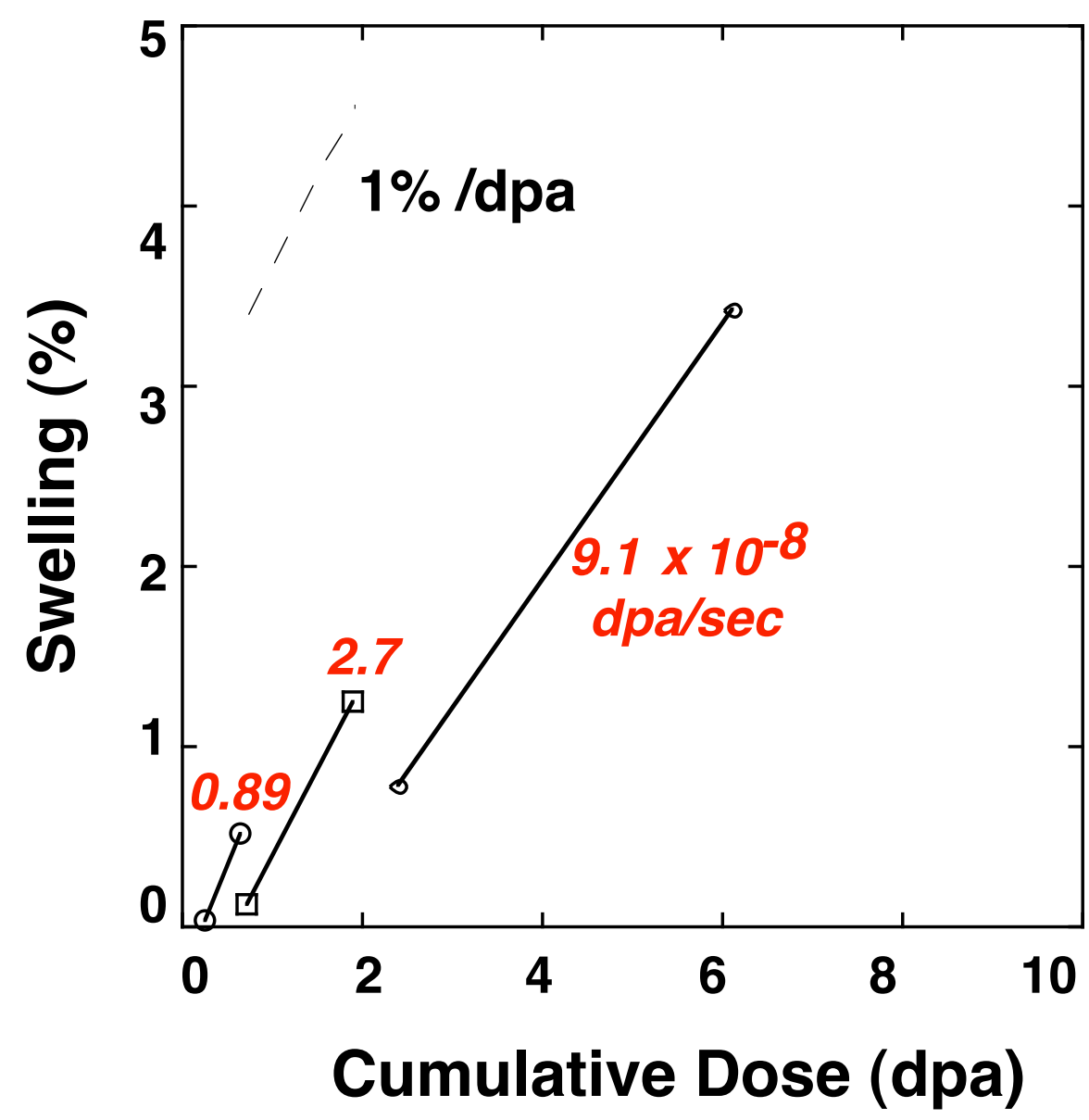


The lowest
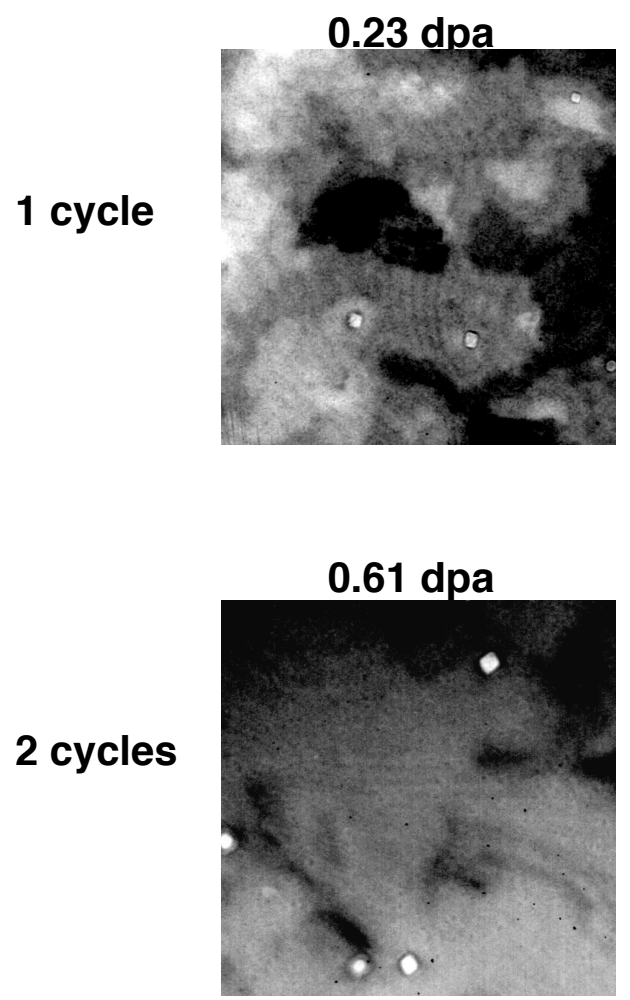

The medium
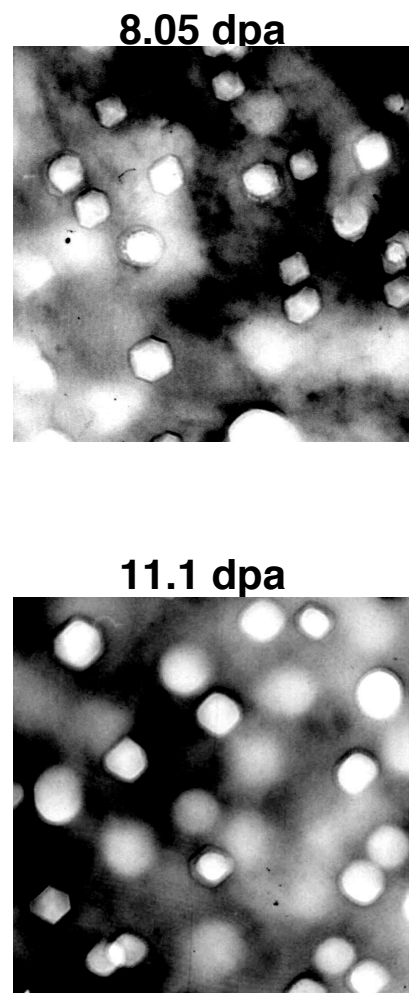

$100 \mathrm{~nm}$
The highest
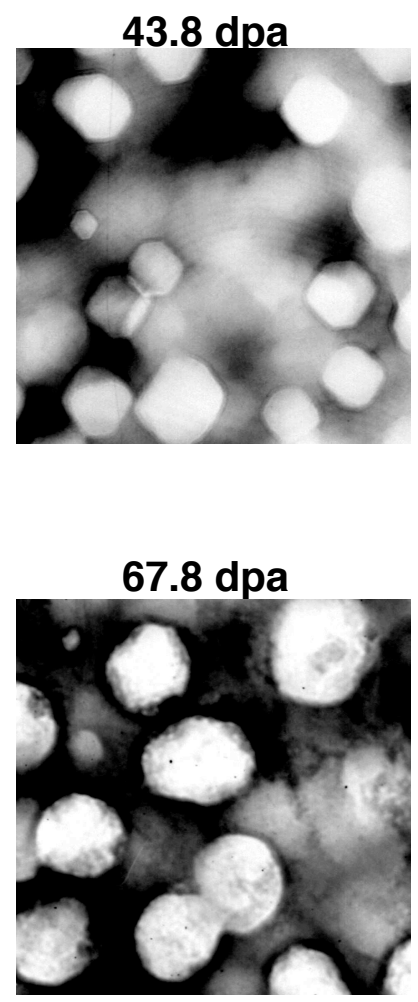

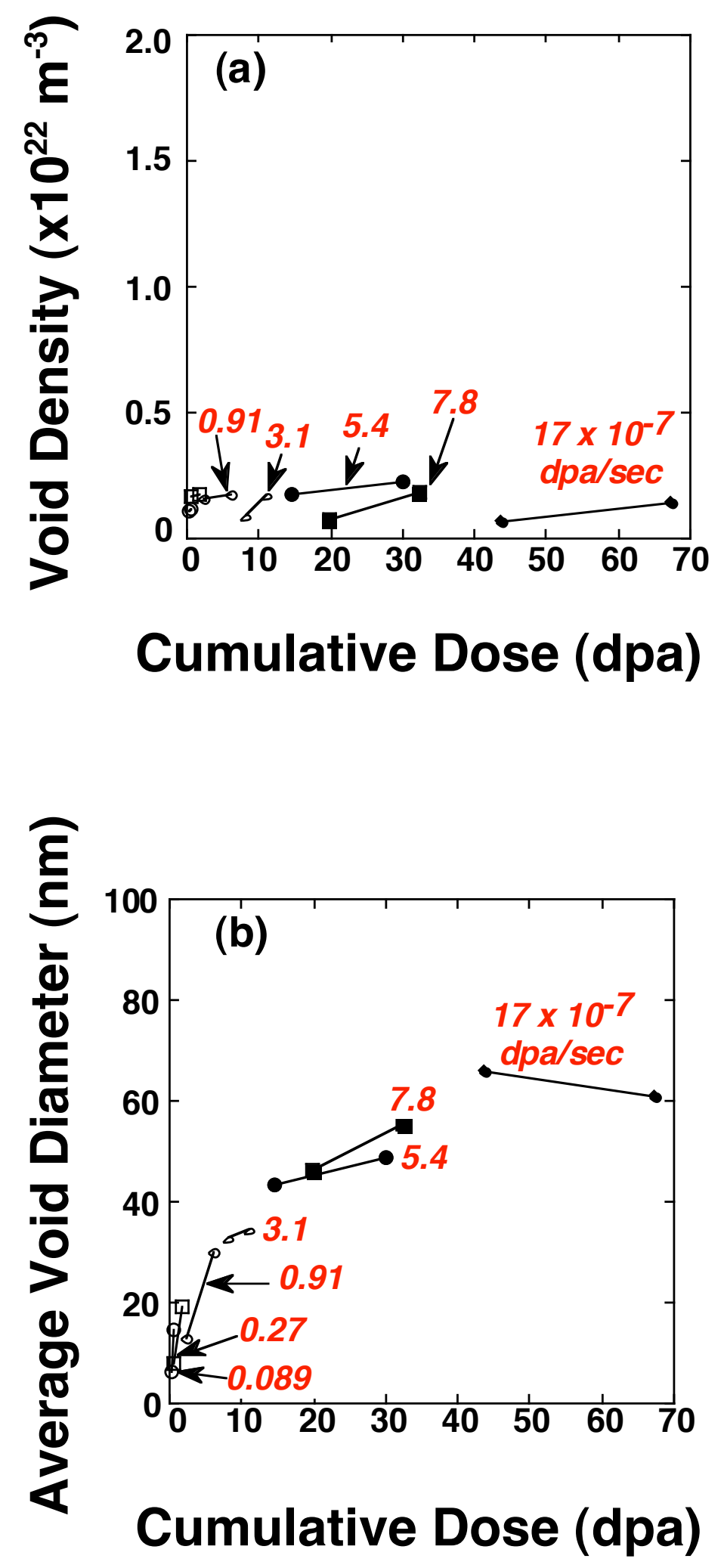
Fe-15Cr-16Ni Fe-15Cr-16Ni-0.25Ti
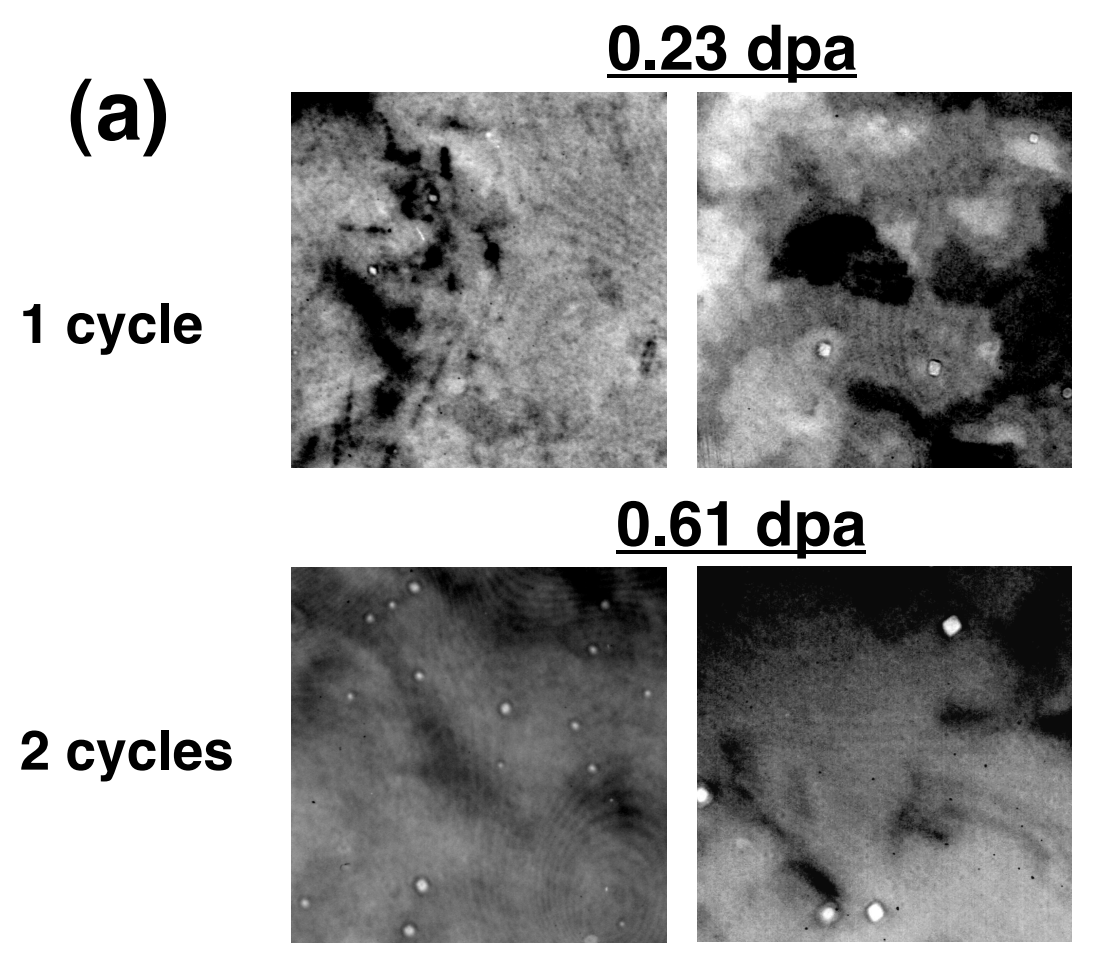

Fe-15Cr-16Ni Fe-15Cr-16Ni-0.25Ti

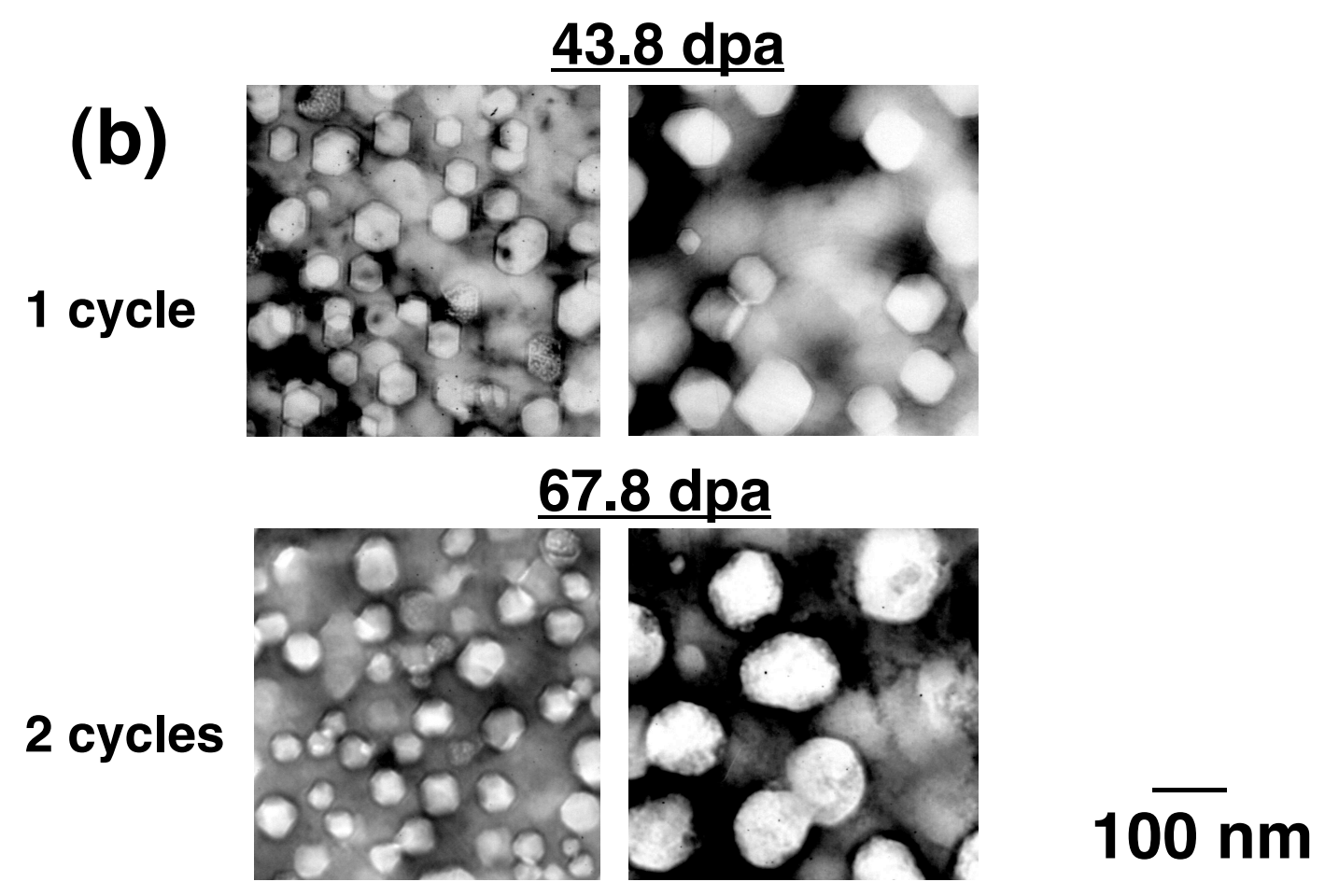


Fe-15Cr-16Ni

Fe-15Cr-16Ni-0.25Ti

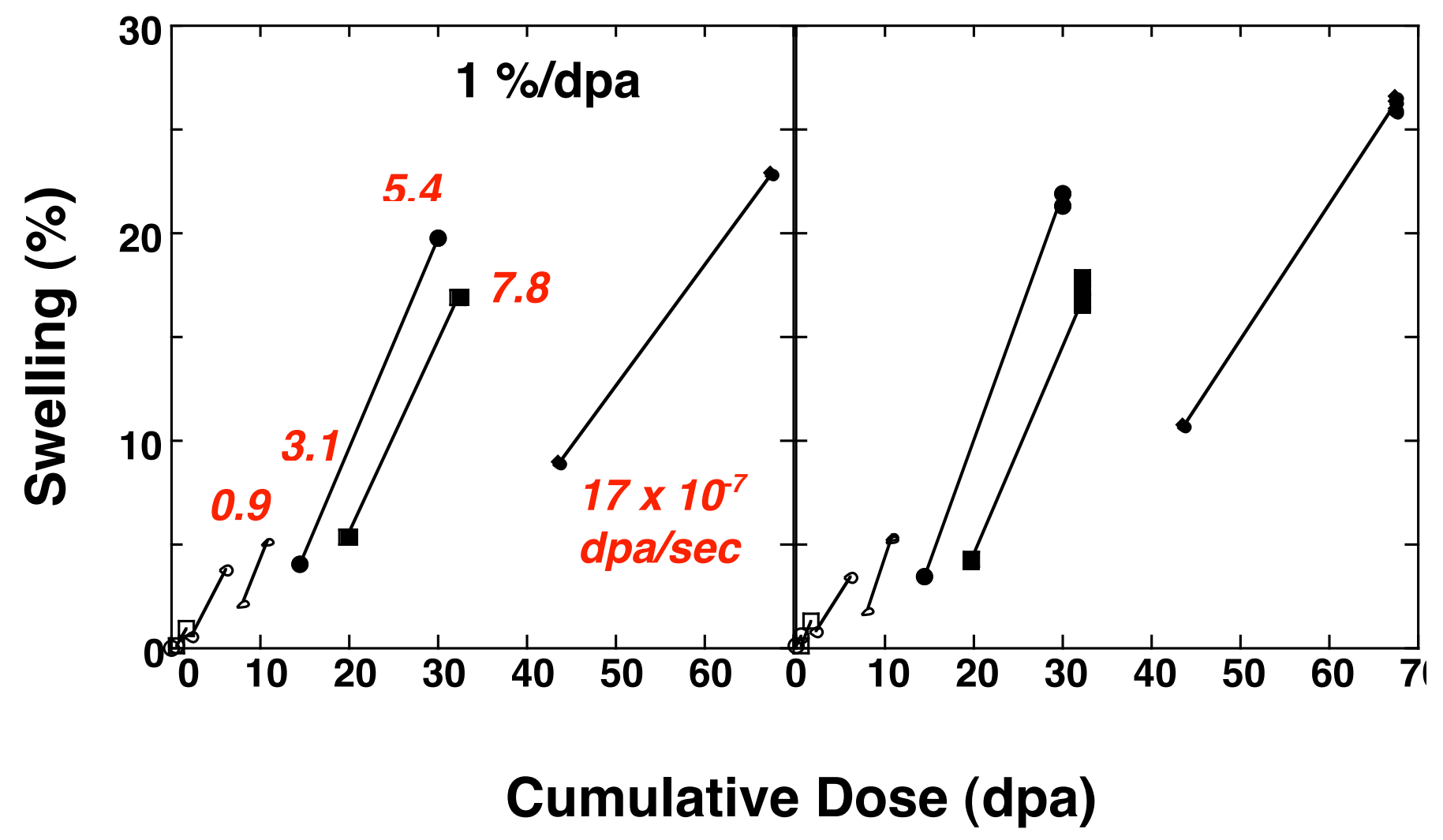




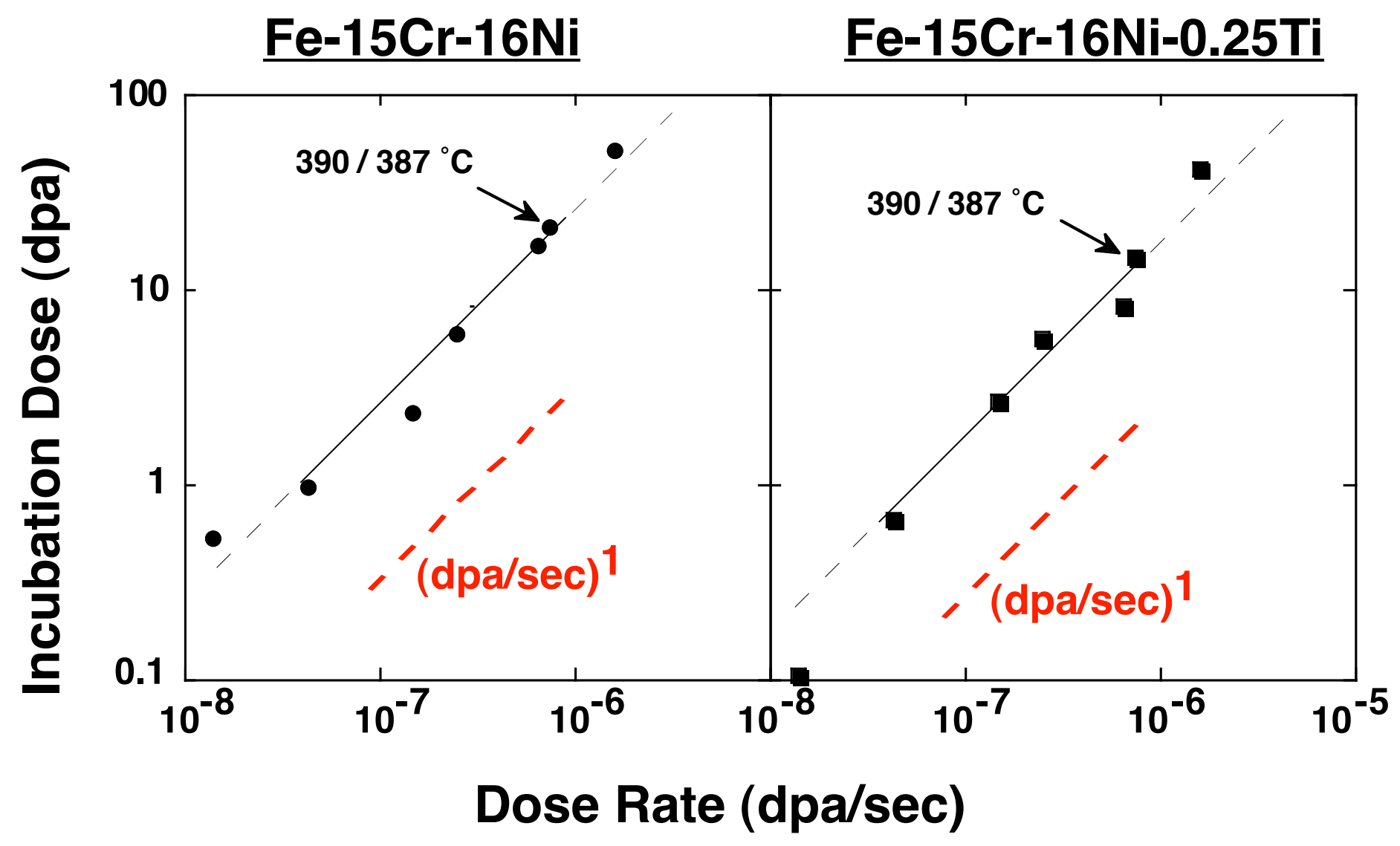




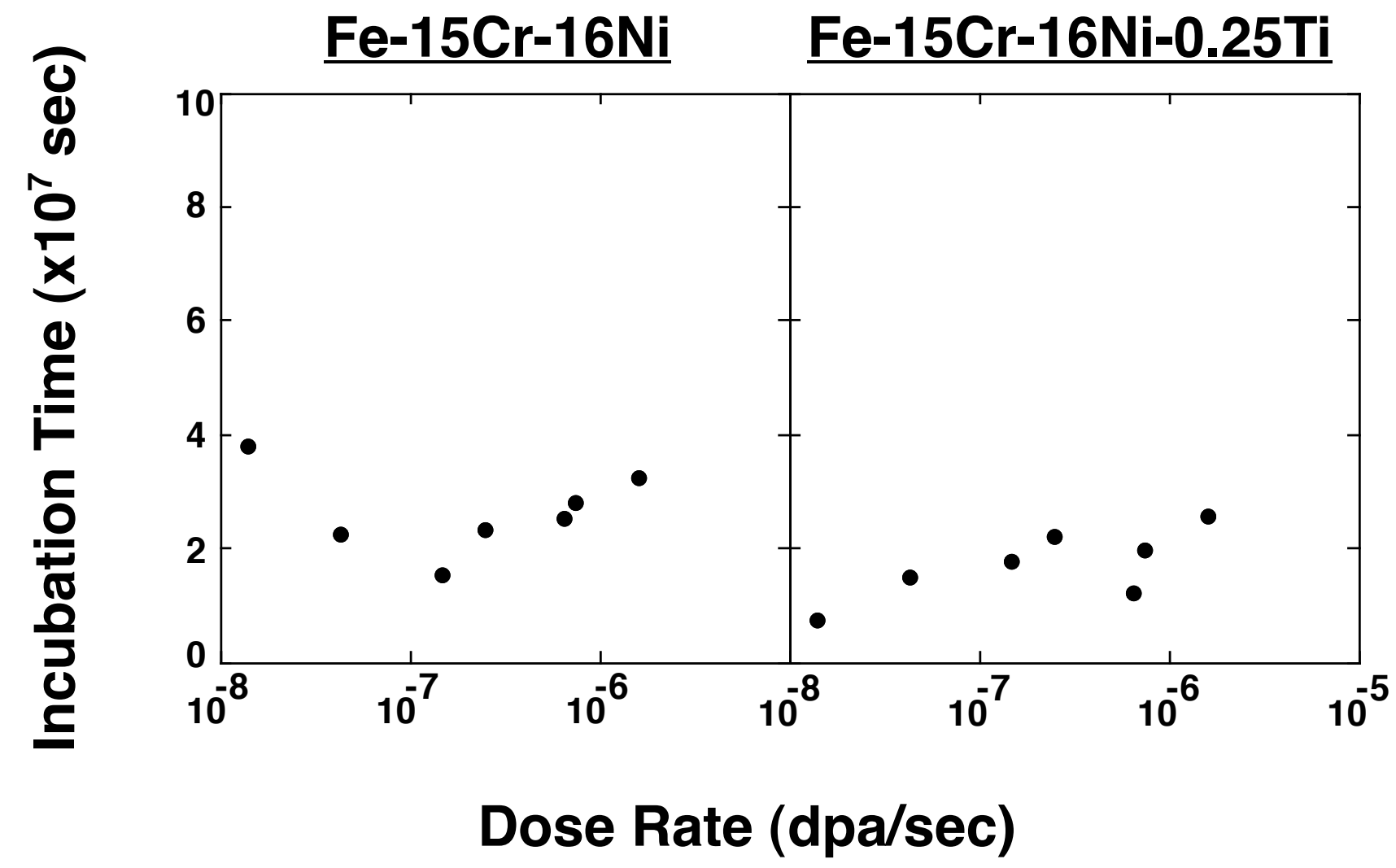




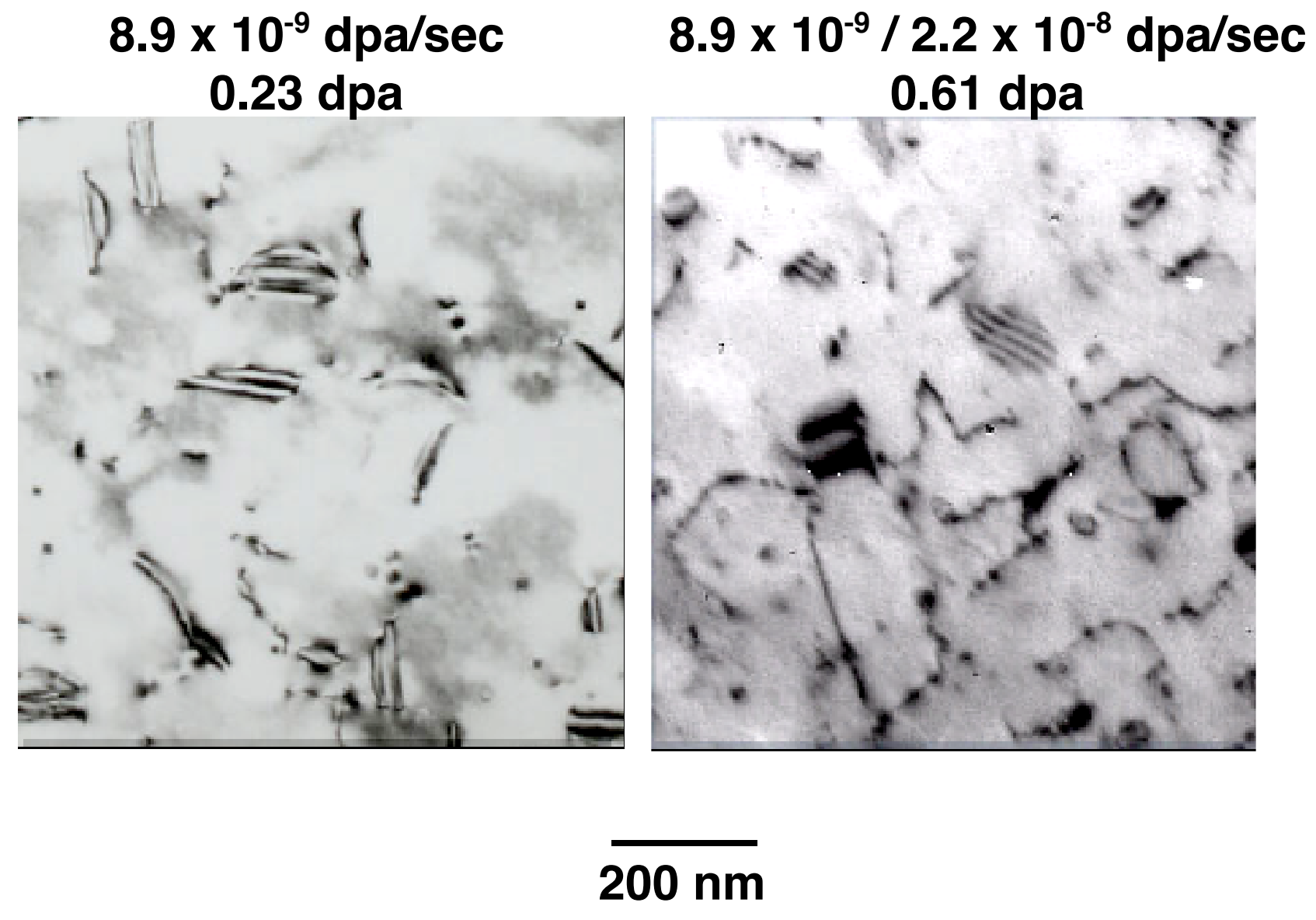




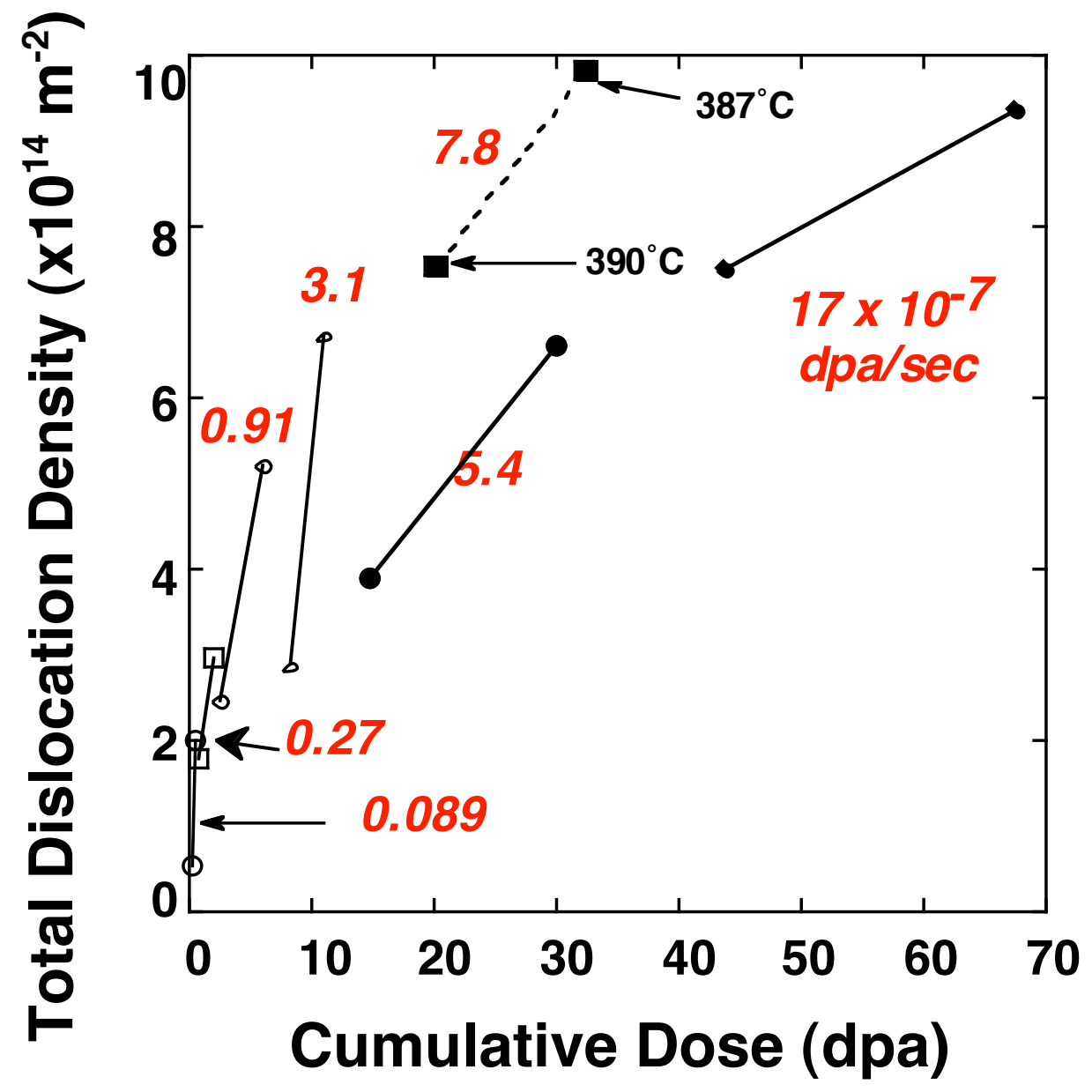




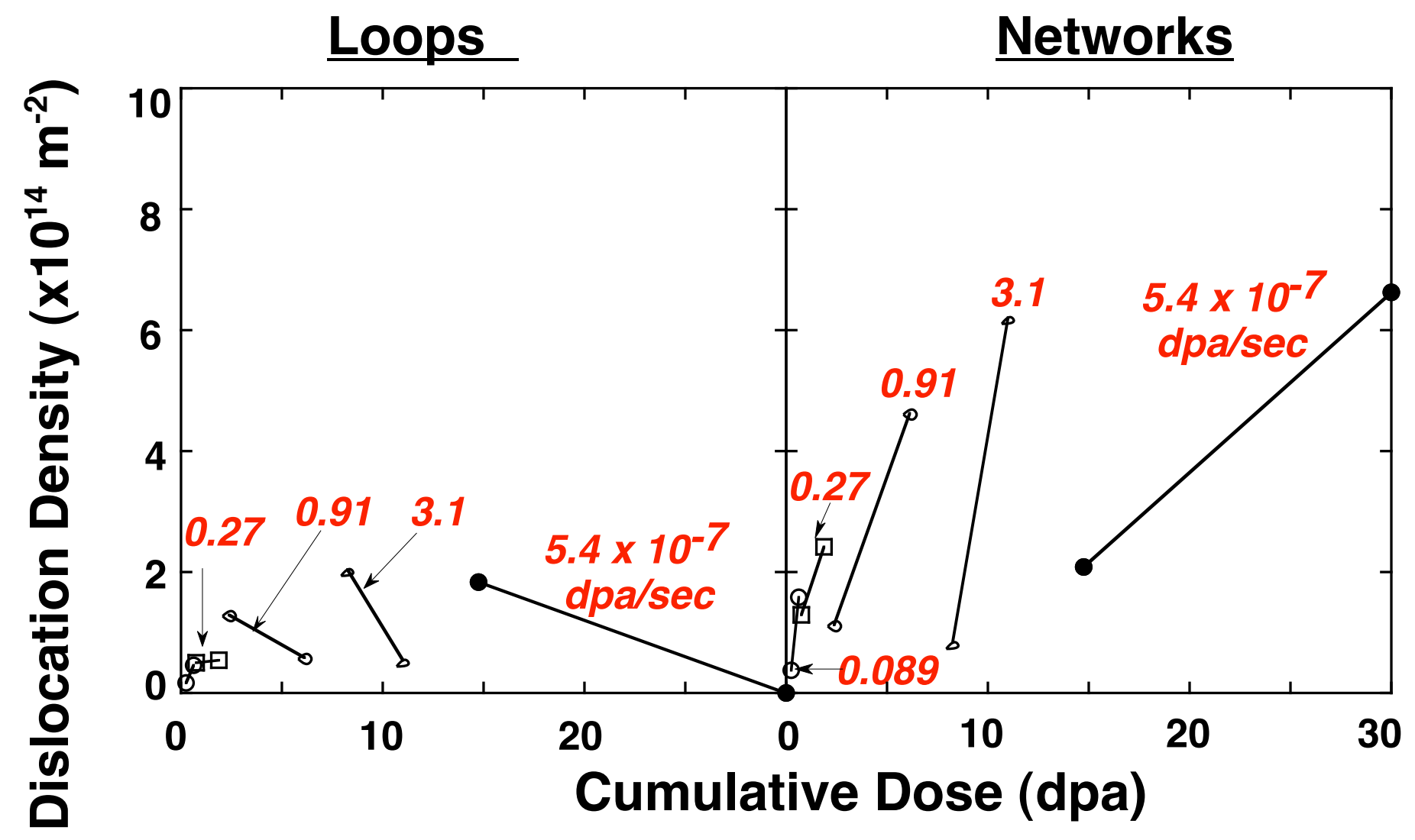


(a)

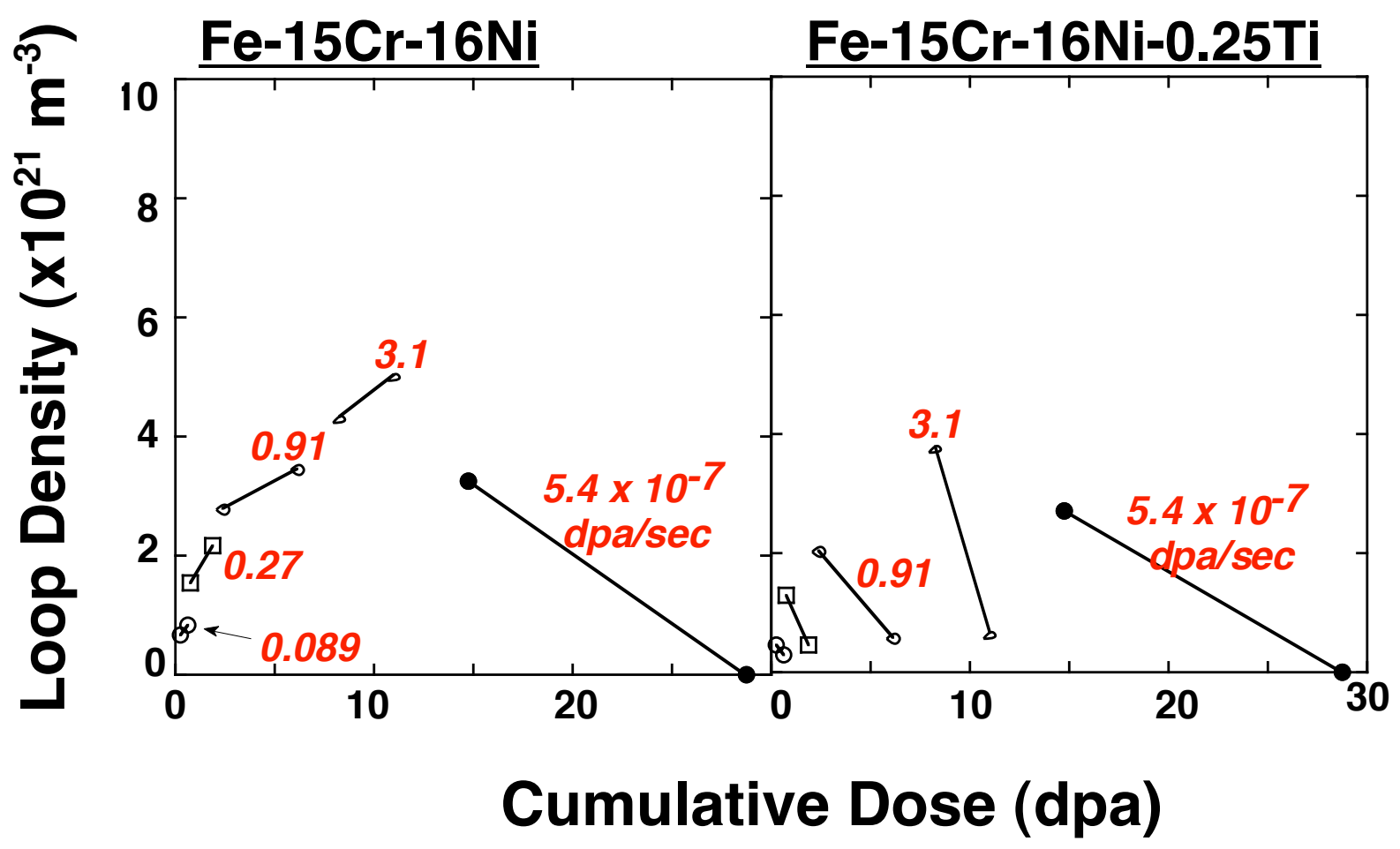

(b)

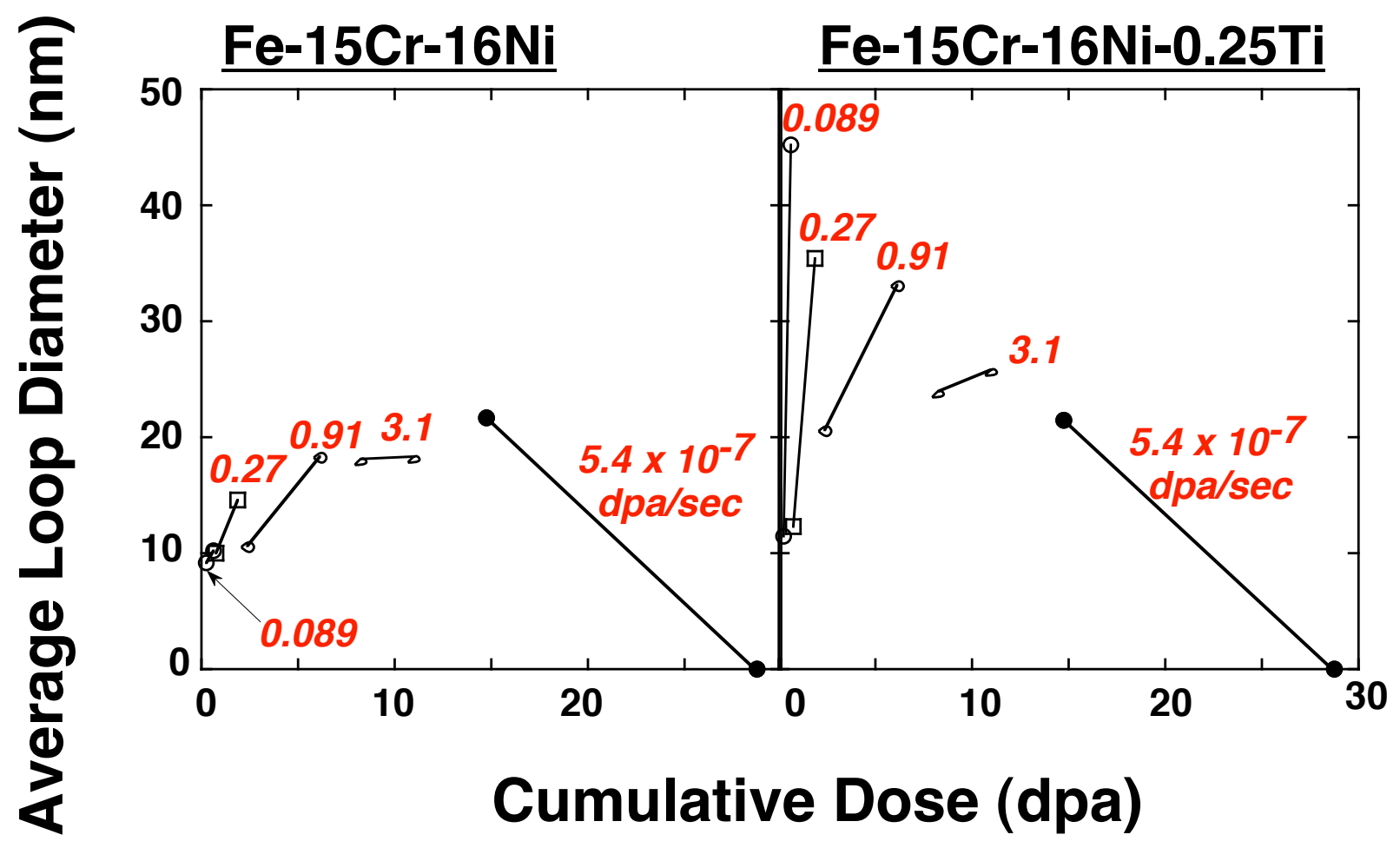




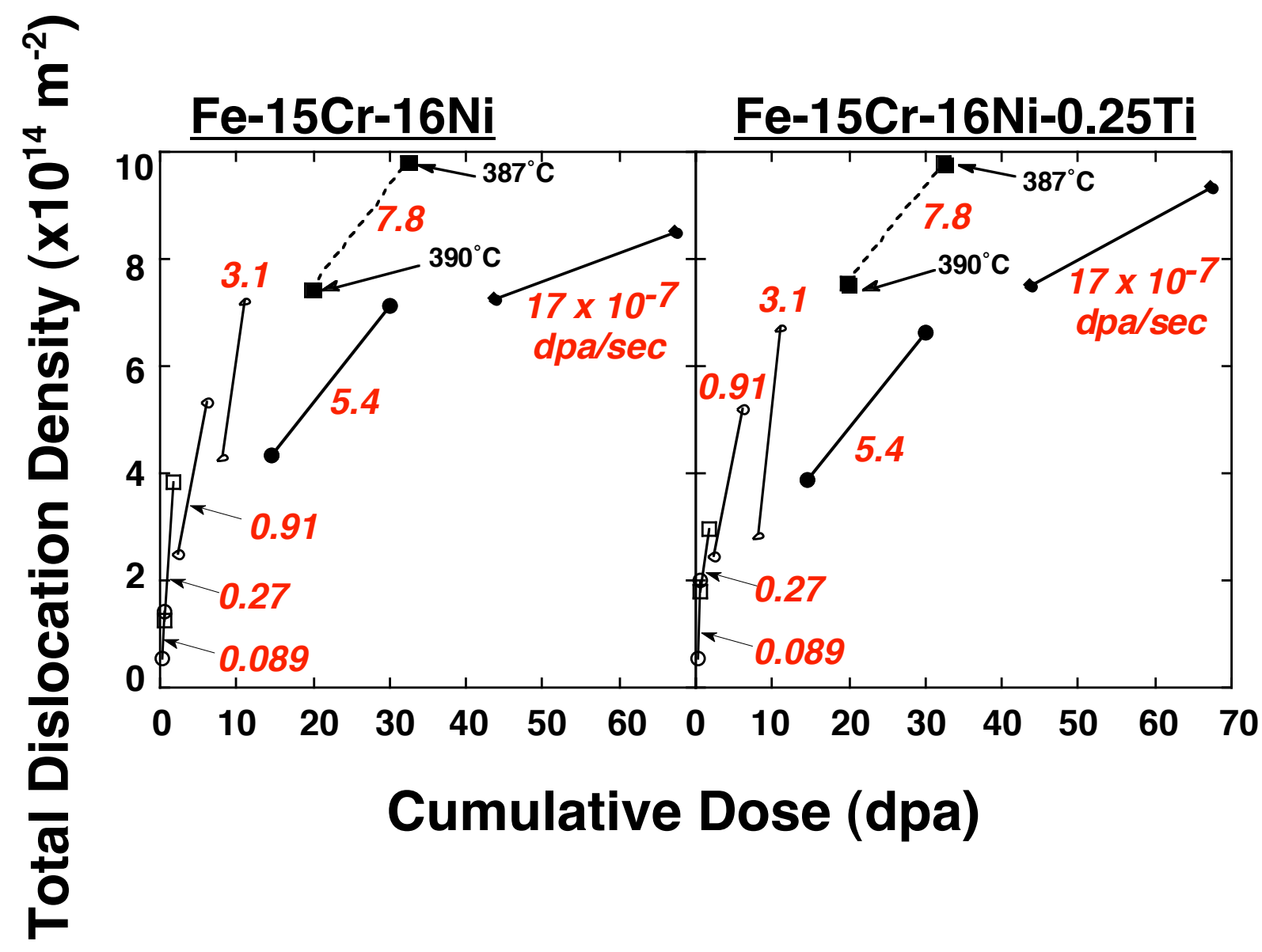



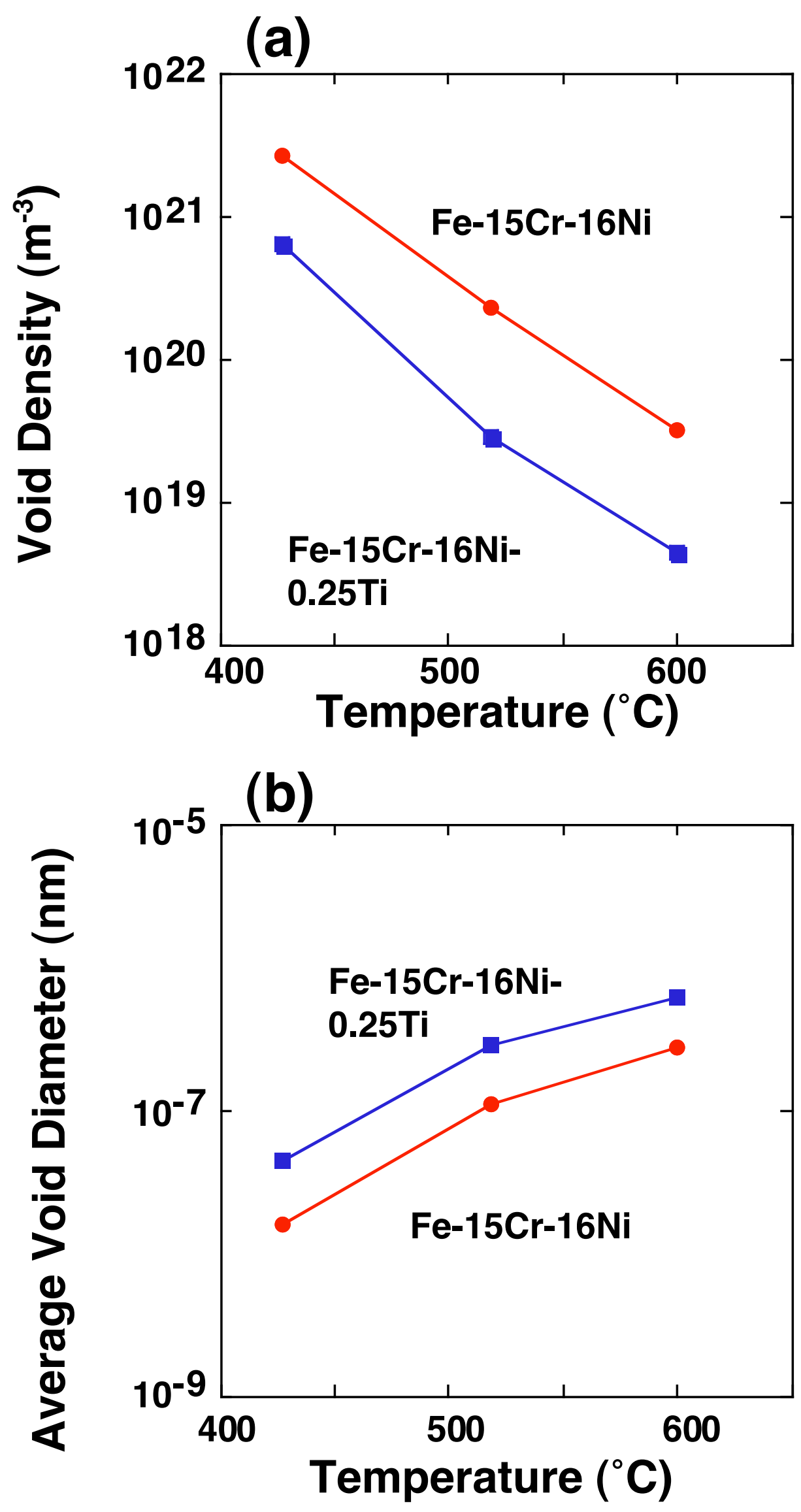


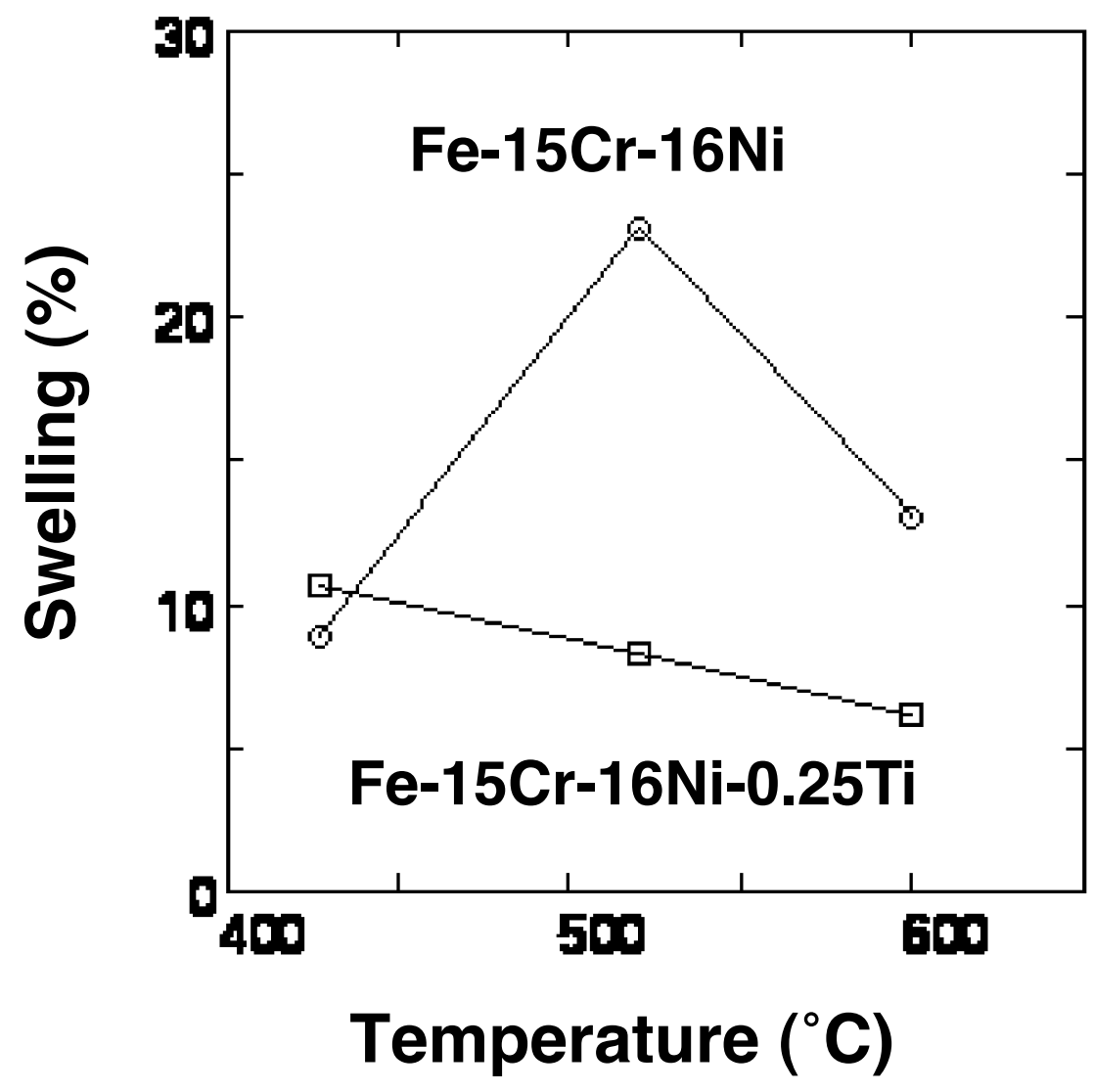


(a)

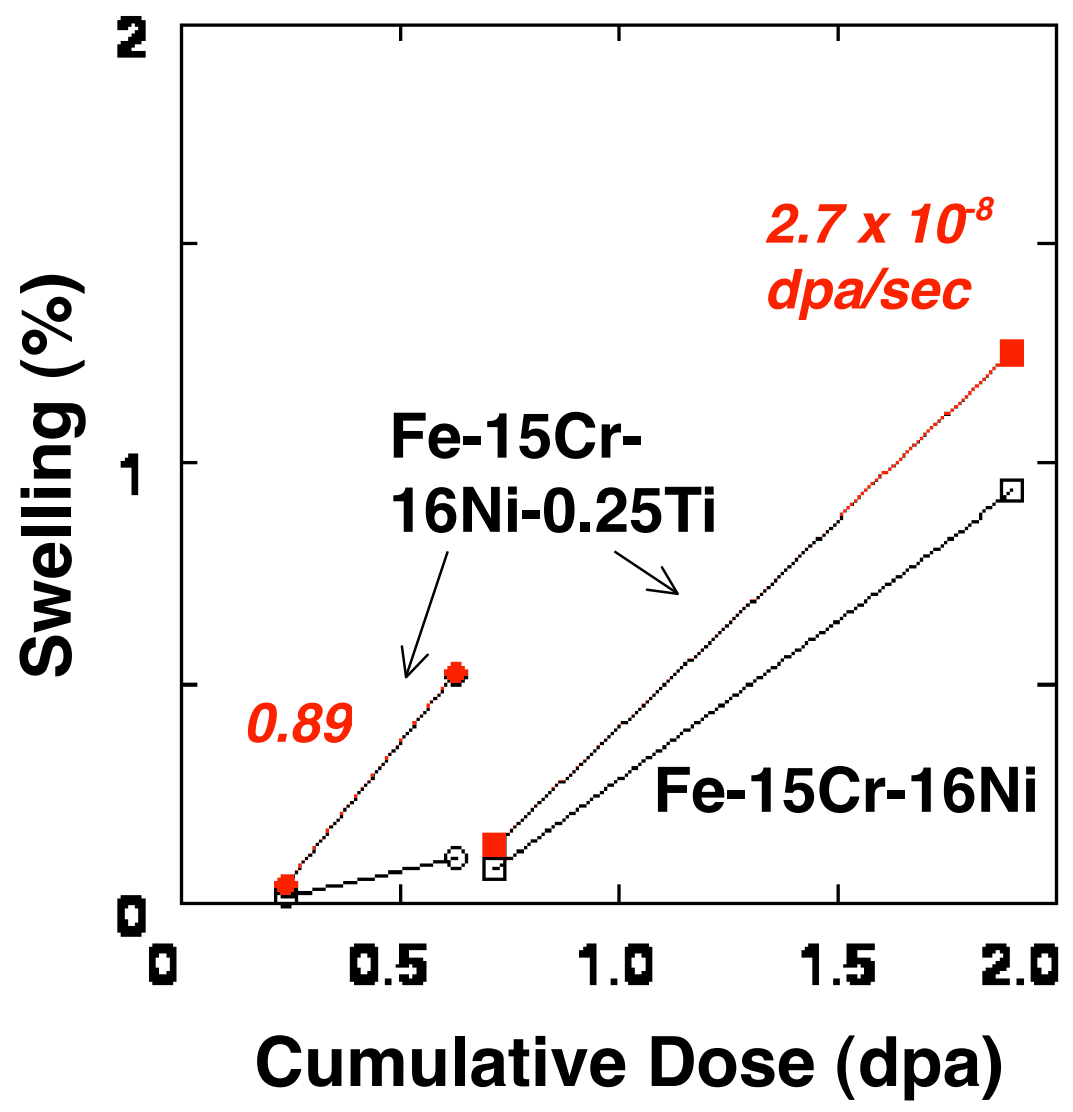

(b)

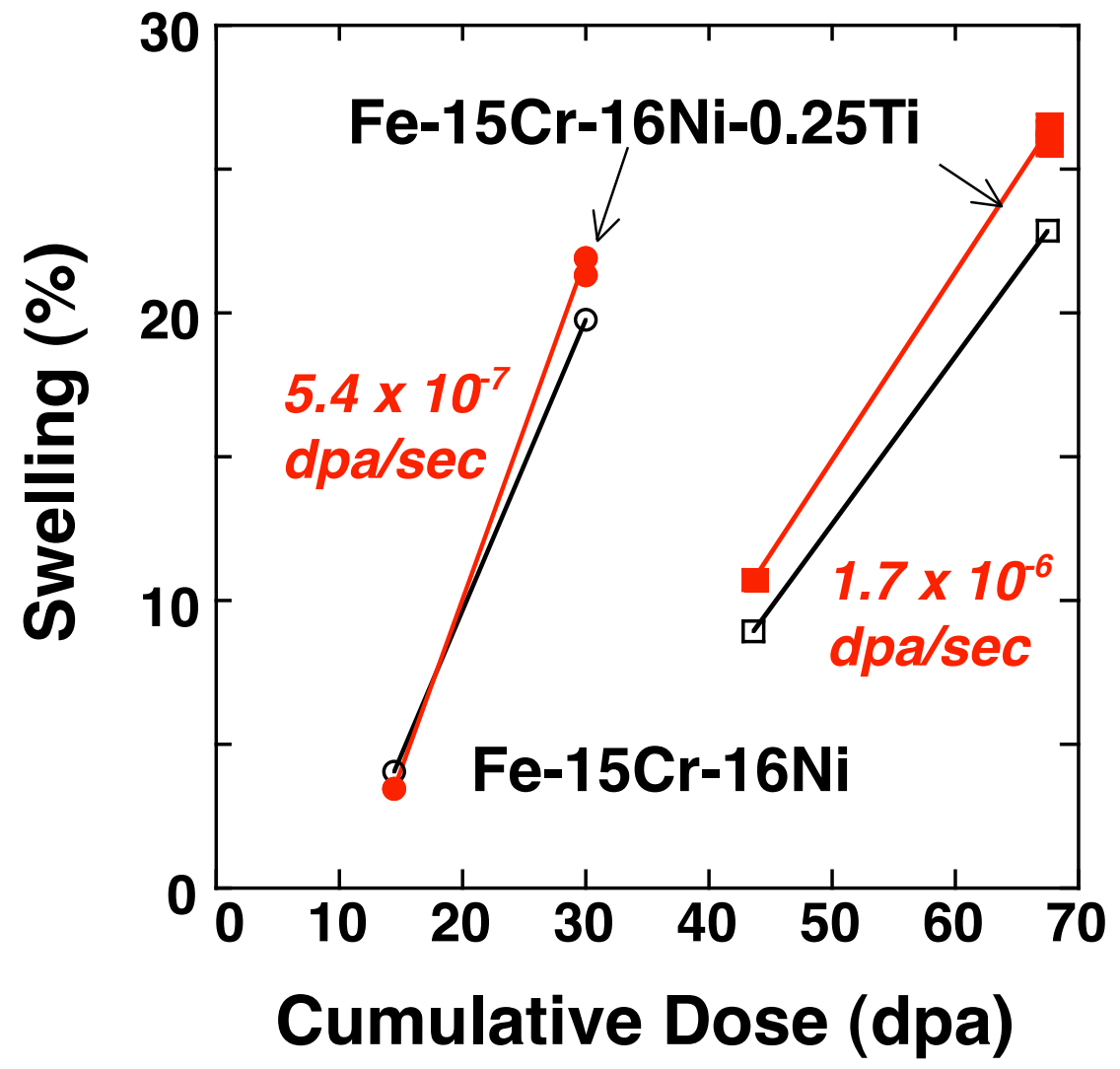


Table 1 Irradiation conditions in this experiment

\begin{tabular}{|c|c|c|c|c|c|}
\hline \multicolumn{2}{|c|}{ Dose Rate (dpa/sec) } & \multicolumn{2}{|c|}{ Dose (dpa) } & \multicolumn{2}{|c|}{ Temperature $\left({ }^{\circ} \mathrm{C}\right)$} \\
\hline$\# 11$ & $\# 12$ & $\# 11$ & $\# 11 \& 12$ & $\# 11$ & $\# 12$ \\
\hline $1.7 \times 10^{-6}$ & $1.4 \times 10^{-6}$ & 43.8 & 67.8 & 427 & 408 \\
\hline${ }^{* 1} 7.8 \times 10^{-7}$ & $9.5 \times 10^{-7}$ & 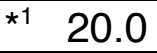 & 32.4 & 390 & 387 \\
\hline $5.4 \times 10^{-7}$ & $8.4 \times 10^{-7}$ & 14.0 & 28.8 & 430 & 424 \\
\hline *2 $3.1 \times 10^{-7}$ & $3.0 \times 10^{-7}$ & *2 8.05 & 11.1 & 411 & 410 \\
\hline $9.1 \times 10^{-8}$ & $2.1 \times 10^{-7}$ & 2.36 & 6.36 & 430 & 431 \\
\hline $2.7 \times 10^{-8}$ & $6.6 \times 10^{-8}$ & 0.71 & 1.87 & 434 & 437 \\
\hline $8.9 \times 10^{-9}$ & $2.2 \times 10^{-8}$ & 0.23 & 0.61 & 436 & 444 \\
\hline
\end{tabular}

${ }^{*} 16.0 \times 10^{-7} \mathrm{dpa} / \mathrm{sec}$ and $15.6 \mathrm{dpa}$ for 2cycles-irradiation specimens

${ }^{*} 2.2 \times 10^{-7} \mathrm{dpa} / \mathrm{sec}$ and $5.69 \mathrm{dpa}$ for 2cycles-irradiation specimens 
Table 2 Previous neutron irradiation studies addressing the effect of titanium addition to pure ternaries on swelling at $\sim 400^{\circ} \mathrm{C}$

\begin{tabular}{|c|c|c|c|c|c|c}
\hline Alloy & Authors & Reactor & dpa & Temperature & dpa/sec & $\begin{array}{c}\text { Change relative to } \\
\text { ternary }\end{array}$ \\
\hline Fe-13Cr-14Ni-0.12Ti & Muroga et al. 1988 & JOYO & 0.4 & $400^{\circ} \mathrm{C}$ & $\sim 1.3 \times 10^{-7}$ & Small reduction \\
\hline Fe-13Cr-14Ni-0.12Ti & Muroga et al 1988 & JOYO & 2.5 & $400^{\circ} \mathrm{C}$ & $\sim 1.3 \times 10^{-7}$ & Small reduction \\
\hline Fe-15Cr-16Ni-0.3Ti & Kawanishi et al.1988 & JOYO & 0.4 & $400^{\circ} \mathrm{C}$ & $\sim 1.3 \times 10^{-7}$ & Small increase \\
\hline Fe-15Cr-16Ni-0.3Ti & Kawanishi et al. 1991 & JOYO & 2.5 & $400^{\circ} \mathrm{C}$ & $\sim 1.3 \times 10^{-7}$ & Small reduction \\
\hline Fe-15Cr-16Ni-0.25Ti & Sekimura et al.1991 & FFTF & 31.5 & $420^{\circ} \mathrm{C}$ & $1.7 \times 10^{-7}$ & Small increase \\
\hline Fe-16Cr-17Ni-0.25Ti & Muroga et al. 1994 & FFTF & 8.4 & $411^{\circ} \mathrm{C}$ & $4.7 \times 10^{-7}$ & Small increase \\
\hline Fe-16Cr-17Ni-0.25Ti & Watanabe et al.1994 & FFTF & 36.1 & $427^{\circ} \mathrm{C}$ & $2.0 \times 10^{-6}$ & $50 \%$ Increase \\
\hline Fe-16Cr-17Ni-0.25Ti & Watanabe et al 1994 & FFTF & 10.7 & $373^{\circ} \mathrm{C}$ & $6.0 \times 10^{-7}$ & Small increase \\
\hline $\begin{array}{c}\text { Fe-15Cr-15Ni-xTi } \\
(x=0.0-1.2)\end{array}$ & Herschbach el al.1993 & PFR & (17) 30,60 & $420^{\circ} \mathrm{C}$ & $\sim 2.0 \times 10^{-6}$ & $\begin{array}{r}100 \% \text { increase for bot } \\
0.5 \% \& 1.2 \% ~ T i\end{array}$ \\
\hline
\end{tabular}


Table 3 Typical values for the calculation of the stacking fault energy

\begin{tabular}{|c|c|c|}
\hline & Symbol & Typical value \\
\hline Shear modulus & $\mathrm{G}$ & $6.5 \times 10^{10} \mathrm{~Pa}$ \\
\hline Poisson's ratio & $\square$ & 0.295 \\
\hline Lattice constant & $\mathrm{a}$ & $3.639 \times 10^{-10} \mathrm{~m}$ \\
\hline Dislocation core radius & $\mathrm{r}_{0}$ & $1.0 \times 10^{-9} \mathrm{~m}$ \\
\hline
\end{tabular}

